\title{
Effect of Broussonetia papyrifera L. silage on blood biochemical parameters, growth performance, meat amino acids and fatty acids compositions in beef cattle
}

\author{
Hui Tao ${ }^{1, a}$, Bingwen $\mathrm{Si}^{1,2, a}$, Wencai $\mathrm{Xu}^{3}$, Yan Tu${ }^{1}$, and Qiyu Diao ${ }^{1, *}$
}

\begin{abstract}
* Corresponding Author: Qiyu Diao Tel: +86-010-82106055, Fax: +86-010-62169105, E-mail: diaogiyu@caas.cn
\end{abstract}

'Feed Research Institute, Chinese Academy of Agricultural Sciences, Key Laboratory of Feed Biotechnology of the Ministry of Agriculture, Beijing 10081, China

${ }^{2}$ National Engineering Research Center of Biological Feed, Beijing 10081, China

3 Jonathan Technology Limited Development Company, Beijing 101314, China

a These authors contributed equally to this research and should be considered as co-first authors.

ORCID

Hui Tao

https://orcid.org/0000-0003-3981-9251

Bingwen $\mathrm{Si}$

https://orcid.org/0000-0001-5050-7078

Wencai Xu

https://orcid.org/0000-0003-0247-4691

Yan Tu

https://orcid.org/0000-0002-4324-6188

Qiyu Diao

https://orcid.org/0000-0002-8037-1471

Submitted Feb 22, 2019; Revised May 17, 2019; Accepted Sept 2, 2019
Objective: The study was conducted to investigate the effects of Broussonetia papyrifera $L$. (B. papyrifera) silage on growth performance, serum biochemical parameters, meat quality, and meat amino acids and fatty acids compositions in beef cattle.

Methods: Sixty-four male Angus beef cattle were assigned to 4 groups with 4 pens in each group and 4 beef cattle in each pen, and fed with the total mixed ration supplemented with $0 \%, 5 \%, 10 \%$, or $15 \%$ B. papyrifera silage for 100 days (control group, $5 \%$ group, $10 \%$ group and $15 \%$ group) separately.

Results: Beef cattle had significantly higher final body weight (BW) in 15\% group, higher average daily gain (ADG) and dry matter intake (DMI) in 5\% group, 10\% group and $15 \%$ group, and higher feed conversion ratio (FCR) in 10\% group and $15 \%$ group. Significantly higher blood superoxide dismutase (SOD) concentration was noted in 15\% group, higher blood total antioxidant capacity (TAC) in $10 \%$ group and $15 \%$ group, lower 8-hydroxydeoxyguanosine (8-OHdG) and malondialdehyde (MDA) in 15\% group. Meat had lower $\mathrm{pH}$ in $15 \%$ group, higher Commission International DeI'Eclairage (CIE) $\mathrm{L}^{*}$ in $5 \%$ group, $10 \%$ group, and $15 \%$ group, and lower drip loss in $15 \%$ group. Greater concentration of meat polyunsaturated fatty acids (PUFA) was observed in 10\% group and 15\% group, and docosahexaenoic acid (DHA) in 15\% group.

Conclusion: Diet with $15 \%$ B. papyrifera silage could improve performance and increase final $\mathrm{BW}, \mathrm{ADG}, \mathrm{DMI}$, and FCR, enhance the antioxidant functions by decreasing blood 8-OHdG and MDA and increasing blood SOD and TAC, improve the meat quality by lowing $\mathrm{pH}$ and drip loss and increasing CIE $\mathrm{L}^{*}$, increase the meat PUFA and DHA concentration. Polyphenols and flavonoids might be the main components responsible for the antioxidant activity and anti-biohydrogenation in the B. papyrifera silage. And B. papyrifera silage could be used as a new feedstuff in beef cattle nutrition.

Keywords: Broussonetia papyrifera Silage; Antioxidant Capacity; Meat Quality; Amino Acids Composition; Fatty Acids Composition; Beef Cattle

\section{INTRODUCTION}

Ruminant products have higher saturated fatty acids (SFA) compared with nonruminants, mainly because of hydrogenation of dietary unsaturated fatty acids by ruminal microbes [1] Feeding strategies have been developed to increase the unsaturated fatty acids of ruminants' products by increasing the rumen bypass unsaturated fatty acids or decreasing ruminal hydrogenation of dietary unsaturated fatty acids [2]. For ruminants, there are great opportunities to explore the potential of additional forages in their diets. Meanwhile, the supplements of plant antioxidant extracts or raw antioxidant plant materials in animal diets is a common practice to improve animal performance, health and products [3]. Broussonetia papyrifera 
L. (B. papyrifera, paper mulberry), a deciduous tree or shrub in the family Moraceae, natively grows in eastern Asia, are mainly used in papermaking [4], feed [5] and medicine [6] industries. There are about 300,000 hectares of B. papyrifera in China, widely distributed in basins of Yellow River, Yangtze River, Pearl River and Mingjiang River. It is reported that certain plants fed to ruminants could reduce the ruminal biohydrogenation [7]. It was found that $B$. papyrifera silage could increase the poly-unsaturated fatty acids (PUFA) concentration in the milk [5]. Besides that, oxidative stress could be very dangerous as no clinical symptoms are obvious, but some metabolites and enzymes in antioxidant defense systems such as vitamins, glutathione peroxidase (GSH-Px), superoxide dismutase (SOD), and catalase (CAT) could prevent oxidative damage, and dietary antioxidants play important roles in preventing damage by free radicals in the system [8]. It is reported that mean levels of total antioxidant capacity (TAC) in shrubs and trees are higher than those in grass, concentrates and timothy hay, which might be beneficial for the TAC status of cattle if they are fed high TAC plants [9]. Many plants contain phytochemicals which have potent antioxidant activities, such as polysaccharides, polyphenolic constituents and antioxidant lignans [10,11]. It is reported that there are antioxidant activities in the fruits, stem, bark and wood of B. papyrifera $[10,11]$. We conducted the experiment to investigate the effects of $B$. papyrifera silage on performance, serum biochemical parameters, meat quality, amino acids and fatty acids composition in male Angus beef cattle.

\section{MATERIALS AND METHODS}

The experimental protocol was approved by the Chinese Academy of Agricultural Sciences Animal Ethics Committee, which was performed in accordance with animal welfare practices and procedures followed the Guidelines for Experimental Animal of the Ministry of Science and Technology (2006, Beijing, China).

\section{Animal and management}

Silage preparation: As the B. papyrifera sapling grew up to about $1.8 \mathrm{~m}$ height, the whole foliage was harvested leaving $20 \mathrm{~cm}$ of stubble. Then the crops were chopped to $2.5 \pm 1.5 \mathrm{~cm}$, they were wrapped in a size of $70 \mathrm{~cm}$ height $\times 70 \mathrm{~cm}$ id and $75 \mathrm{~kg}$ with a silage wrapper, and then fermented without additive for 45 days before feeding.

\section{Animal management}

Sixty-four male Angus beef cattle with initial body weight (BW) at $495 \pm 16.9 \mathrm{~kg}$ were allocated in 4 groups randomly with 4 pens in each group and 4 individuals in each pen, i.e., 4 replicates in each group and 4 individuals in each replicate, and given ad libitum access to feed and water. The cattle in the control group were fed on the original TMR in the feedlot, and the other 3 treatment groups were fed on the new TMR with $5 \%$ (5\% group), $10 \%$ (10\% group) or $15 \%$ (15\% group) of $B$. papyrifera silage preparation, separately. The four different TMRs were adjusted as isonitrogenous and isoenergetic diets (Table 1 ) and the fatty acids composition of the diets were shown in Table 2. The beef cattle were fed approximately $110 \%$ as expected consumption at 7:00 and 15:00 separately, and the weight of residual was recorded before new feeding were delivered. And the delivery amount was adjusted according to the previous day's consumption. The feeding adaption period was 7 days, and the experiment period was 100 days.

\section{Sampling and measurements}

The dietary samples, including feeding ingredients, TMRs and residual were collected every 2 weeks during the experiment for analyzing the dry matter (DM), crude fat (ether extract), ash, neutral detergent fiber (NDF), and acid detergent fiber (ADF) according to the method reported by van Soest et al [12] and Goering and van Soest [13], respectively. The $\mathrm{pH}$ value of $B$. papyrifera silage was 5.04 and the nutrient composition of B. papyrifera silage is shown in Table 1.

At the end of the trial, two beef cattle were selected from each pen and had $24 \mathrm{~h}$ feed withdrawal before slaughter. And blood samples were collected from jugular vein for serum. Live BW was recorded before the animals were electrically stunned and slaughtered by exsanguination according to the animals ethics committee of CAAS mentioned above. The hot carcass weight of cattle was recorded for calculating the dressing rate. And then the Longissimus dorsi muscle was taken on both sides between 12th thoracic and 5th lumbar vertebrae. The right Longissimus dorsi muscle was kept in $-4^{\circ} \mathrm{C}$ for determination of the meat quality after slaughter. Furthermore, the left Longissimus dorsi muscle samples were kept in $-80^{\circ} \mathrm{C}$ for analysis of amino acids and fatty acids composition.

Color determination: The cut surface of the muscle was placed at ambient temperature for $30 \mathrm{~min}$, and then lightness $\left(\mathrm{CIE} \mathrm{L}^{\star}\right)$, redness $\left(\mathrm{CIE} \mathrm{a}^{\star}\right)$ and yellowness $\left(\mathrm{CIE} \mathrm{b}^{\star}\right)$ values, were measured according to the CIE color system (Commission International DeI’Eclairage, 1976) using Minolta CR-100 Chroma Meter (Minolta Camera Co. Ltd, Osaka, Japan) equipped with an $8.0 \mathrm{~mm}$ aperture and illuminant C. CIE $L^{\star}, a^{\star}$, and $b^{\star}$ of meat were recorded 3 times at different positions on the measured surface and averaged for statistical analysis. $\mathrm{pH}$ was determined at the same site for muscle color, using a portable Model HI9025 meter (Hanna Instruments, Woonsocket, RI, USA) with a combined electrode by insertion into the at 12th vertebrae end of Longissimus dorsi muscle and having a two-point calibration ( $\mathrm{pH} 4.01$ and 
Table 1. Ingredients and nutrition levels of diets (air dry basis, \%)

\begin{tabular}{|c|c|c|c|c|c|}
\hline Items & Control group & $5 \%$ group & $10 \%$ group & $15 \%$ group & B. papyrifera silage \\
\hline \multicolumn{6}{|l|}{ Ingredients } \\
\hline Flaked corn & 27.0 & 27.0 & 27.0 & 27.0 & - \\
\hline Extruded soybean & 2.90 & 2.50 & 2.50 & 2.50 & - \\
\hline Wheat bran & 7.72 & 8.00 & 8.00 & 6.85 & - \\
\hline Rice bran & 26.1 & 25.8 & 26.0 & 26.4 & - \\
\hline $\mathrm{NaHCO}_{3}$ & 0.72 & 0.72 & 0.72 & 0.72 & - \\
\hline Premix ${ }^{1)}$ & 1.0 & 1.0 & 1.0 & 1.0 & - \\
\hline Corn straw ammoniation & 17.3 & 12.5 & 7.5 & 2.5 & - \\
\hline B. papyrifera silage & 0.0 & 5.0 & 10.0 & 15.0 & - \\
\hline Total & 100 & 100 & 100 & 100 & - \\
\hline $\mathrm{EE}(\% \mathrm{DM})$ & 3.43 & 3.40 & 3.51 & 3.58 & 3.34 \\
\hline NDF (\% DM) & 45.2 & 43.6 & 42.0 & 40.3 & 45.5 \\
\hline ADF (\% DM) & 24.9 & 24.1 & 23.4 & 22.8 & 29.0 \\
\hline Ash (\% DM) & 6.78 & 6.94 & 7.12 & 7.26 & 11.6 \\
\hline Water soluble carbohydrate (\% DM) & - & - & - & - & 4.18 \\
\hline Lactic acid (g/kg DM) & - & - & - & - & 87.3 \\
\hline Acetic acid (g/kg DM) & - & - & - & - & 20.9 \\
\hline Propionic acid (g/kg DM) & - & - & - & - & 1.1 \\
\hline Lactic acid/total acid & - & - & - & - & 79.75 \\
\hline Acetic acid/total acid & - & - & - & - & 19.23 \\
\hline Propionic acid/total acid & - & - & - & - & 1.02 \\
\hline
\end{tabular}

B. papyrifera, Broussonetia papyrifera; DM, dry matter; $C P$, crude protein; $E E$, ether extract; NDF, neutral detergent fiber; ADF, acid detergent fiber.

1) One kilogram of premix contains 600,000 IU vitamin A, 100,000 IU vitamin D, 4,000 IU vitamin E, 3,000 mg Fe, 2,000 mg Cu, 2,500 mg Mn, 8,000 mg Zn, 60 mg Se, 100 $\mathrm{mg} \mathrm{l}, 20 \mathrm{mg}$ Co.

6.99).

Cooking loss determination: The muscle samples were cut

Table 2. Fatty acids composition of the diets

\begin{tabular}{lcccc}
\hline $\begin{array}{c}\text { \% of total } \\
\text { fatty acids }\end{array}$ & $\begin{array}{c}\text { Control } \\
\text { group }\end{array}$ & $\begin{array}{c}\mathbf{5 \%} \\
\text { group }\end{array}$ & $\begin{array}{c}\mathbf{1 0 \%} \\
\text { group }\end{array}$ & $\begin{array}{c}\mathbf{1 5 \%} \\
\text { group }\end{array}$ \\
\hline C8:0 & 0.01 & 0.01 & 0.01 & 0.02 \\
C10:0 & 0.02 & 0.03 & 0.02 & 0.03 \\
C12:0 & 0.09 & 0.08 & 0.07 & 0.08 \\
C14:0 & 1.45 & 1.47 & 1.42 & 1.43 \\
C15:0 & 0.03 & 0.02 & 0.03 & 0.03 \\
C16:0 & 17.6 & 16.4 & 15.9 & 16.3 \\
C17:0 & 0.12 & 0.17 & 0.15 & 0.11 \\
C18:0 & 2.95 & 3.14 & 4.04 & 3.83 \\
C18:1n9c & 23.7 & 24.2 & 25.3 & 24.9 \\
C18:2n6c & 51.4 & 51.9 & 50.9 & 50.7 \\
C18:3n3 & 2.27 & 2.14 & 2.42 & 2.09 \\
C20:0 & 0.42 & 0.45 & 0.35 & 0.56 \\
C22:0 & 0.14 & 0.13 & 0.09 & 0.11 \\
C24:0 & 0.03 & 0.05 & 0.03 & 0.04 \\
\hline
\end{tabular}

into cube pieces with $1.5 \mathrm{~cm}$ per side and weighed, then cooked in sealed plastic bags in $80^{\circ} \mathrm{C}$ water baths until the internal temperature of the meat reached $75^{\circ} \mathrm{C}$, which was measured by a 5SC-TT-T-30-36 thermoscouple (Omega Engineering Inc., Stamford, CT, USA) fixed in the geometrical center of the sample. Cooked samples were cooled, fluids were wiped and reweighed. The cooking loss was calculated as a percentage of weight loss [14].

Drip loss measurement: Approximately 80 to $100 \mathrm{~g}$ muscle samples were cut form Longissimus dorsi muscle samples and immediately weighed and suspended in an inflated bag without touching the bag, then they were placed in $4^{\circ} \mathrm{C}$ refrigerators for $24 \mathrm{~h}$, and then reweighed [15].

Shearing force: The muscle samples were cut along the muscle fibers as rectangular cross-section slices of $1.0 \mathrm{~cm} \times 1.0 \mathrm{~cm}$ $\times 5.0 \mathrm{~cm}$ (length). Then the sample was sheared vertically using a TA. XT Plus/50 texture analyzer (Stable Micro Systems, Surrey, UK). A crosshead speed of $200 \mathrm{~mm} / \mathrm{min}$ and a $5-\mathrm{kN}$ load cell calibrated to read over a range of 0 to $100 \mathrm{~N}$ were applied. Six replicates of each sample were measured to calculate the 
average value.

Blood biochemical parameters: Blood metabolites, immune parameters and anti-oxidation biomarkers were determined by a biochemical auto-analyzer (Hitachi automatic biochemical analyzer 7600, Tokyo, Japan) using commercially available kits: total protein (TP), albumin (ALB), globulin (GLB), nonesterified fatty acid (NEFA), blood urea nitrogen (BUN), total cholesterol (TC), triglyceride (TG), glucose (GLU), high density lipoprotein cholesterol (HDL-C), low density lipoprotein (LDL-C), immunoglobulin A (IgA), IgG, IgM, CAT, SOD, GSH-Px, TAC, 8-hydroxydeoxyguanosine (8-OHdG), advanced oxidation protein products (AOPP), and malondialdehyde (MDA) according to the manufacturer's instructions. The activity of tumor necrosis factora (TNFa) was measured by a micro plate reader (BioTek ELX800, BioTek, Winooski, VT, USA) with commercially available kits.

Amino acids analysis: About $100 \mathrm{~g}$ of muscle samples were homogenized and moved to a tub with $10 \mathrm{~mL}$ of $6 \mathrm{~mol} / \mathrm{L} \mathrm{HCl}$, then snap frozen with liquid nitrogen and later vacuumeddried. After post-column ninhydrin derivatization, they were hydrolyzed in evacuated sealed tubes with $0.1 \%$ phenol for $22 \mathrm{~h}$ at $110^{\circ} \mathrm{C}$. The solution was diluted and filtered by a $0.45-$ $\mu \mathrm{m}$ filter, and then the amino acids were determined using an automated amino acid analyzer (Hitachi L-8900, Japan) according to AOAC (1995). The sulfur-containing amino acids were detected according to an oxidation hydrolysis method: about $100 \mathrm{mg}$ meat samples were dissolved in hydrogen peroxide with formic acid (1:9) for $16 \mathrm{~h}$ and then added with $0.5 \mathrm{~mL}$ sodium bisulfate and $8 \mathrm{~mL} 6.8 \mathrm{~mol} / \mathrm{L}$ of $\mathrm{HCl}$, after hydrolysis for $24 \mathrm{~h}$ at $110^{\circ} \mathrm{C}$, the solution was added with $0.75 \mathrm{~mL}$ sodium citrate and $0.15 \mathrm{~mL}$ sodium hydroxide before filtered by a $0.45-\mu \mathrm{m}$ filter. And then sulfur-containing amino acids in the solution was determined by the amino acid analyzer. Tryptophan was determined according to an alkaline hydrolysis method: about $100 \mathrm{mg}$ muscle samples were dissolved in $4 \mathrm{~mol} / \mathrm{L}$ of lithium hydroxide and then hydrolyzed for $20 \mathrm{~h}$ at $110^{\circ} \mathrm{C}$. Thereafter, the solution was adjusted for $\mathrm{pH}$ by adding $\mathrm{HCl}$ and filtered through a $0.45-\mu \mathrm{m}$ filter. Then the solution loaded on the amino acid analyzer.

Fatty acids analysis: Total lipids of meat were extracted using a mixture of polar and non-polar solvents, and then fatty acids were methylated into fatty acid methyl esters (FAME)
[16]. The fatty acid profile was determined by gas chromatography (Shimadzu GC-2010, Tokyo, Japan) equipped with flame ionization detector and split injection, $100 \mathrm{~m}$ length, $0.25 \mathrm{~mm}$ i.d., $0.2 \mu \mathrm{m}$ thickness capillary gas chromatography column (SP-2560; Supelco, Bellefonte, PA, USA). The initial oven temperature was $150^{\circ} \mathrm{C}$, which was held for $5 \mathrm{~min}$, then increased to $200^{\circ} \mathrm{C}$ at a rate of $2^{\circ} \mathrm{C} / \mathrm{min}$ and held for $10 \mathrm{~min}$, then increased to $220^{\circ} \mathrm{C}$ at $5^{\circ} \mathrm{C} / \mathrm{min}$ and held for $35 \mathrm{~min}$. Helium was used as carrier gas at a flow rate of $1 \mathrm{~mL} / \mathrm{min}$. The injector was set at $260^{\circ} \mathrm{C}$, and the detector was set at $280^{\circ} \mathrm{C}$. FAMEs were identified by compared with the retention times of the standards. The standards were FAME MixC4C24 (Sigma 18919, Deisenhofen, Germany).

\section{Statistical analysis}

The data on growth performance, dry matter intake (DMI), feed conversion rate, blood biochemical parameters, meat quality traits, amino acids and fatty acids composition were compared using PROC MIXED of SAS (version 9.2, SAS Institute Inc., Gary, NC, USA) with polynomial contrasts to test the effects of mixing ratio for dietary B. papyrifera silage, a randomized complete block design was used with diet as fixed effects and beef cattle within diet as a random effect. The data were expressed as mean and accompanied by standard error of the mean. Differences were considered significant at $\mathrm{p}<0.05$.

\section{RESULTS}

\section{Performance}

Beef cattle in 15\% group had higher final BW than those in other groups, and beef cattle in 5\%,10\%, or $15 \%$ group had higher average daily gain (ADG), DMI, and feed conversion rate $(\mathrm{FCR})$ than that in control group $(\mathrm{p}<0.05)$ (Table 3$)$.

\section{Blood metabolites, immune and antioxidant functions Blood biochemical indexes of beef, TP, ALB, GLB, NEFA, BUN, TC, TG, GLU, HDL-C, and LDL-C, and blood immune function parameters, Ig A, Ig G, Ig M, and TNFa, and anti- oxidation indexes, AOPP, GSH-Px, and CAT, were not affected by the diets supplemented with $B$. papyrifera silage $(\mathrm{p}>0.1)$. \\ The beef cattle in $10 \%$ group and $15 \%$ group had signifi-}

Table 3. Effect of Broussonetia papyrifera silage on performance of black Angus

\begin{tabular}{lcccccc}
\hline Items & Control group & $\mathbf{5 \%}$ group & $\mathbf{1 0 \%}$ group & $\mathbf{1 5 \%}$ group & SEM & p-value \\
\hline Initial BW (kg) & 494 & 494 & 495 & 496 & $616^{\mathrm{a}}$ & 17.4 \\
Final BW (kg) & $585^{\mathrm{b}}$ & $596^{\mathrm{ab}}$ & $608^{\mathrm{ab}}$ & $1.18^{\mathrm{a}}$ & 6.7 & 0.013 \\
ADG (kg/d) & $0.91^{\mathrm{b}}$ & $1.10^{\mathrm{a}}$ & $1.13^{\mathrm{a}}$ & $8.45^{\mathrm{a}}$ & 0.05 & 0.03 \\
DMI (kg/d) & $7.16^{\mathrm{b}}$ & $8.23^{\mathrm{a}}$ & $8.44^{\mathrm{a}}$ & $0.14^{\mathrm{a}}$ & 0.001 & 0.04 \\
FCR & $0.12^{\mathrm{c}}$ & $0.13^{\mathrm{b}}$ & $0.14^{\mathrm{a}}$ & 0.04 \\
\hline
\end{tabular}

SEM, standard error of the mean; BW, body weight; $A D G$, average daily gain; DMI, dry matter intake; FCR, feed conversion rate.

${ }^{a-c}$ Means within row with different superscripts differ significantly $(p<0.05)$. 
cantly higher TAC in blood serum than that in control group or $5 \%$ group, but blood TAC in 5\% group had no significant difference compared with that in control group. Blood SOD in $15 \%$ was significantly higher than that in control group, $5 \%$ group or $10 \%$ group, but no significant difference was observed among control group, 5\% group and $10 \%$ group. The beef cattle in $15 \%$ group had higher blood $8-\mathrm{OHdG}$ than that in control group, $5 \%$ group or $10 \%$ group, but no significant difference was observed among control group, 5\% group, and $10 \%$ group. Blood MDA was significantly lower in 15\% group than in control group or 5\% group, but no significant difference among control group, $5 \%$ group and $10 \%$ group (Table 4 ).

\section{Meat quality traits}

Diets supplemented with $B$. papyrifera silage had no effect on dressing rate of beef cattle compared with that in the control group ( $\mathrm{p}>0.05)$. Meat $\mathrm{pH}$ was lower in $15 \%$ group than that in control group, $5 \%$ group or $10 \%$ group, but there was no significant difference in meat $\mathrm{pH}$ between control group and $5 \%$ group or $10 \%$ group $(p<0.05)$. Beef cattle had significantly higher $\mathrm{CIE} \mathrm{L}^{*}$ in $5 \%$ group, $10 \%$ group, and $15 \%$ group than that in the control group $(\mathrm{p}<0.05)$. CIE $\mathrm{a}^{*}$ was higher in
$10 \%$ group than that in the control group or $15 \%$ group $(\mathrm{p}<$ 0.05 ), but there is no difference in $\mathrm{CIE} \mathrm{a}^{*}$ between $5 \%$ group and $10 \%$ group. The diet with $15 \%$ of B. papyrifera silage significantly decreased the drip loss of meat compared with the control group, but there was no significant difference among $5 \%$ group, $10 \%$ group, and $15 \%$ group. B. papyrifera silage had no significant effect on CIE $b^{\star}$ of meat, cooking loss and shearing force of meat (Table 5).

\section{Amino acids and fatty acids composition in meat}

No significantly differences were observed in amino acids composition between groups ( $p>0.05$ ) (Table 6).

C12:0 was significantly lower in 10\% group and 15\% group than that in control group ( $\mathrm{p}<0.05)$, but there was no significant difference between 5\% group and control group. C18:2n6c was significantly higher in $15 \%$ group than that in control group or $5 \%$ group $(\mathrm{p}<0.05)$, but no significant difference among control group, $5 \%$ group and 10\% group. C18:3n 3 was significantly higher in 5\% group, 10\% group, and $15 \%$ group than that in control group $(\mathrm{p}<0.05)$. C22:3n6 was significantly higher in $15 \%$ group than that in control group, $5 \%$ group, or $10 \%$ group $(\mathrm{p}<0.05)$, but no difference was

Table 4. Effect of Broussonetia papyrifera silage levels on blood biochemical parameters, immune indexes and anti-oxidant indexes of black Angus

\begin{tabular}{|c|c|c|c|c|c|c|}
\hline Items & Control group & $5 \%$ group & $10 \%$ group & $15 \%$ group & SEM & $p$-value \\
\hline \multicolumn{7}{|l|}{ Biochemical indexes } \\
\hline $\mathrm{TP}(\mathrm{g} / \mathrm{L})$ & 75.4 & 76.3 & 75.3 & 79.5 & 3.06 & 0.96 \\
\hline$A L B(g / L)$ & 24.5 & 22.1 & 24.3 & 25.6 & 0.87 & 0.57 \\
\hline $\mathrm{GLB}(\mathrm{g} / \mathrm{L})$ & 50.9 & 54.2 & 51.0 & 53.9 & 2.49 & 0.96 \\
\hline NEFA $(\mu \mathrm{mol} / \mathrm{L})$ & 482 & 496 & 538 & 514 & 12.7 & 0.49 \\
\hline BUN (mmol/L) & 3.88 & 3.58 & 3.63 & 4.05 & 0.15 & 0.67 \\
\hline $\mathrm{TC}(\mathrm{mmol} / \mathrm{L})$ & 3.30 & 3.39 & 3.40 & 3.14 & 0.16 & 0.94 \\
\hline TG (mmol/L) & 0.11 & 0.12 & 0.15 & 0.13 & 0.011 & 0.76 \\
\hline GLU (mmol/L) & 5.43 & 4.30 & 5.30 & 5.60 & 0.31 & 0.48 \\
\hline $\mathrm{HDL}-\mathrm{C}(\mathrm{mmol} / \mathrm{L})$ & 2.28 & 2.40 & 2.33 & 2.19 & 0.077 & 0.42 \\
\hline LDL-C (mmol/L) & 0.71 & 0.73 & 0.81 & 0.69 & 0.044 & 0.84 \\
\hline \multicolumn{7}{|l|}{ Immune indexes } \\
\hline $\lg A(g / L)$ & 0.79 & 0.93 & 0.89 & 0.83 & 0.064 & 0.91 \\
\hline $\lg G(g / L)$ & 8.36 & 9.24 & 9.46 & 7.79 & 0.29 & 0.12 \\
\hline $\lg M(g / L)$ & 0.61 & 0.71 & 0.74 & 0.64 & 0.046 & 0.78 \\
\hline TNFa (ng/mL) & 1.46 & 1.50 & 1.45 & 1.32 & 0.045 & 0.57 \\
\hline \multicolumn{7}{|c|}{ Anti-oxidation indexes } \\
\hline $\mathrm{SOD}(\mathrm{U} / \mathrm{mL})$ & $131^{b}$ & $131^{b}$ & $134^{\mathrm{b}}$ & $151^{\mathrm{a}}$ & 3.22 & 0.043 \\
\hline $\mathrm{TAC}(\mathrm{U} / \mathrm{mL})$ & $11.8^{b}$ & $12.3^{b}$ & $14.2^{\mathrm{a}}$ & $15.7^{\mathrm{a}}$ & 0.51 & 0.002 \\
\hline 8-OHdG (ng/mL) & $0.57^{\mathrm{a}}$ & $0.51^{\mathrm{a}}$ & $0.48^{\mathrm{ab}}$ & $0.33^{b}$ & 0.020 & 0.024 \\
\hline AOPP $(\mu \mathrm{mol} / \mathrm{L})$ & 19.7 & 19.4 & 19.4 & 18.1 & 0.40 & 0.48 \\
\hline MDA ( $\mu \mathrm{mol} / \mathrm{L})$ & $3.84^{\mathrm{a}}$ & $3.66^{a}$ & $3.21^{\mathrm{ab}}$ & $2.62^{b}$ & 0.18 & 0.033 \\
\hline GSH-Px (U/mL) & 849 & 833 & 842 & 837 & 10.3 & 0.96 \\
\hline CAT (U/mL) & 5.93 & 4.00 & 5.10 & 4.52 & 0.27 & 0.062 \\
\hline
\end{tabular}

SEM, standard error of the mean; TP, total protein; ALB, albumin; GLB, globulin; NEFA, non-esterified fatty acid; BUN, blood urea nitrogen; TC, total cholesterol; TG, total glyceride; GLU, glucose; HDL-C, high density lipoprotein cholesterol; LDL-C, low density lipoprotein cholesterol; Ig, immunoglobulin; TNF $\alpha$, tumor necrosis factor $\alpha$; SOD, superoxide dismutase; TAC, total antioxidant capacity; 8-OHdG, 8-hydroxydeoxyguanosine; AOPP, advanced oxidation protein products; MDA, malondialdehyde; GSH-Px, glutathione peroxidase; CAT, catalase.

a,b Means within row with different superscripts differ significantly $(p<0.05)$. 
Table 5. Effect of Broussonetia papyrifera silage levels on beef quality of black Angus

\begin{tabular}{|c|c|c|c|c|c|c|}
\hline Items & Control group & $5 \%$ group & $10 \%$ group & $15 \%$ group & SEM & $\mathrm{p}$-value \\
\hline Dressing rate (\%) & 57.4 & 56.5 & 57.2 & 56.66 & 0.32 & 0.83 \\
\hline pH & $6.54^{\mathrm{a}}$ & $6.69^{\mathrm{a}}$ & $6.50^{\mathrm{a}}$ & $6.16^{b}$ & 0.056 & $<0.0001$ \\
\hline CIE L* & $25.0^{\mathrm{b}}$ & $27.4^{a}$ & $27.7^{\mathrm{a}}$ & $28.9^{\mathrm{a}}$ & 0.44 & 0.004 \\
\hline $\mathrm{CIE} \mathrm{a}^{*}$ & $8.57^{b}$ & $12.05^{\mathrm{ab}}$ & $15.10^{\mathrm{a}}$ & $9.72^{b}$ & 0.83 & 0.009 \\
\hline CIE b* & 4.72 & 4.53 & 4.64 & 4.92 & 0.16 & 0.88 \\
\hline Cooking loss (\%) & 29.8 & 30.5 & 28.5 & 28.7 & 0.54 & 0.22 \\
\hline Drip loss (\%) & $19.6^{\mathrm{a}}$ & $16.9^{a b}$ & $16.1^{\mathrm{ab}}$ & $13.3^{b}$ & 0.82 & 0.029 \\
\hline Shearing force (N) & 32.7 & 35.5 & 33.3 & 33.4 & 0.85 & 0.71 \\
\hline
\end{tabular}

SEM, standard error of the mean; CIE, Commission International Del'Eclairage.

${ }^{a, b}$ Means within row with different superscripts differ significantly $(p<0.05)$.

Table 6. Effect of Broussonetia papyrifera silage levels on amino acids composition of meat in black Angus

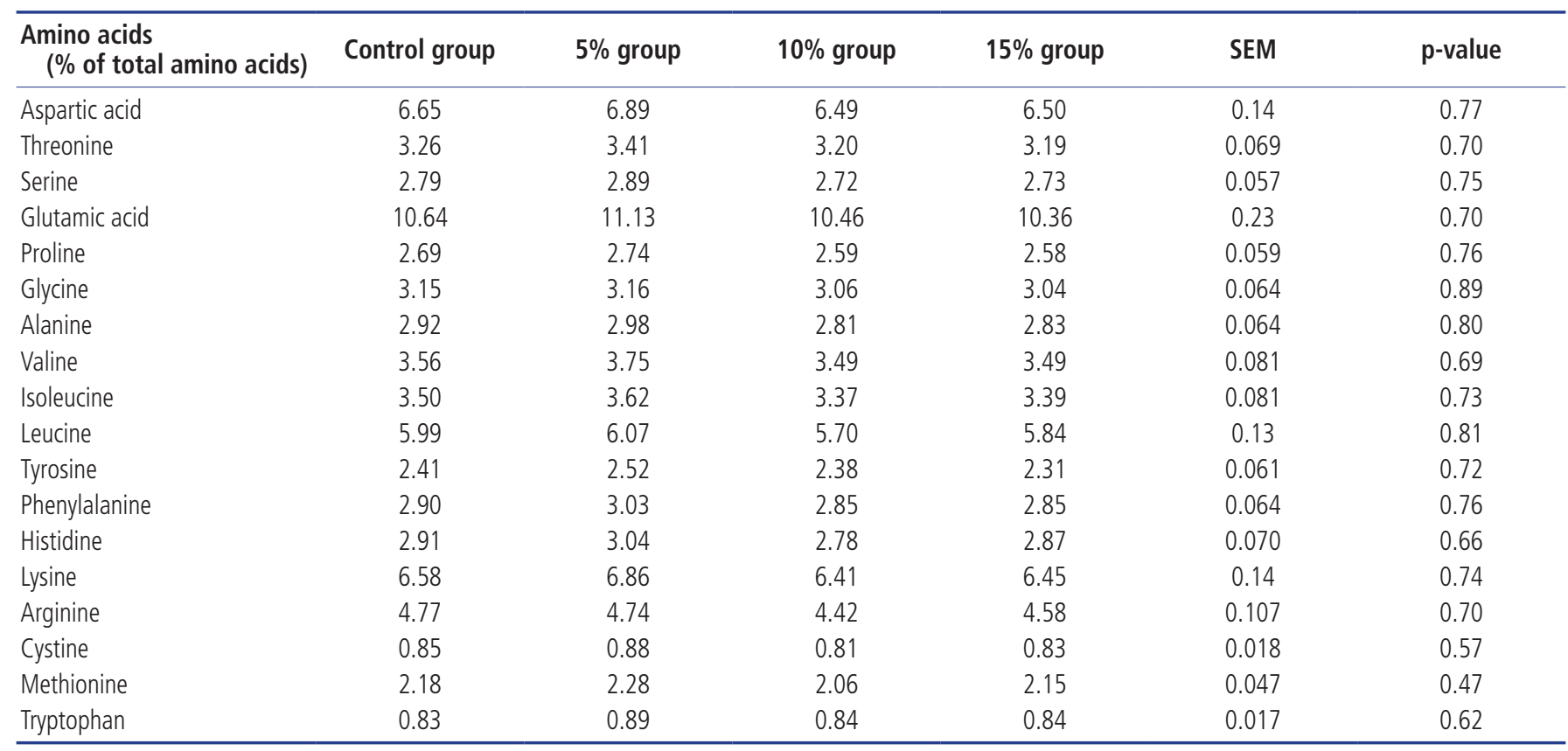

SEM, standard error of the mean.

observed among control group, 5\% group and 10\% group. C22:6n 3 was significantly higher in $5 \%$ group, $10 \%$ group, or $15 \%$ group than that in control group, and C22:6n 3 was significantly higher in $15 \%$ group than that in $5 \%$ group or $10 \%$ group $(\mathrm{p}<0.05)$. The PUFA was significantly higher in $10 \%$ group and $15 \%$ group than that in control group, but no significant difference between control group and $5 \%$ group (Table 7).

\section{DISCUSSION}

\section{Performance}

Beef cattle had significantly higher DMI in 5\% group, $10 \%$ group, and $15 \%$ group than that in control group $(\mathrm{p}<0.05)$. It is reported that catalytic foliage supplementation to low-quality roughages may enhance nutrient utilization in sheep [17], and foliage supplementation increased total feed intake of goats [18] with which our result of DMI was consistent. However, our results were different from the results that $B$. papyrifera silage decreased the DMI in dairy cattle [5], which may have been due to the replacement of low quality forage with high quality forage in diets for beef cattle, not like the low quality forage used in the diets for dairy cattle decreasing the feed intake, high quality forage could increase the DMI in beef cattle.

Beef cattle had higher ADG and FCR in all treatment groups than that in control group, which was consistent with the result reported by Patra that foliage supplementation resulted in increased ADG [18], as it is likely due to increased intakes of digestible nutrients by the ruminants.

\section{Blood metabolites, immune and antioxidant}


Table 7. Effect of Broussonetia papyrifera silage levels on fatty acids composition in meat of black Angus

\begin{tabular}{|c|c|c|c|c|c|c|}
\hline $\begin{array}{l}\text { Fatty acids } \\
\text { ( } \% \text { total fatty acids) }\end{array}$ & Control group & $5 \%$ group & $10 \%$ group & $15 \%$ group & SEM & $p$-value \\
\hline $\mathrm{C} 8: 0$ & 0.03 & 0.05 & 0.04 & 0.03 & 0.003 & 0.16 \\
\hline C10:0 & 0.06 & 0.05 & 0.04 & 0.04 & 0.002 & 0.19 \\
\hline C12:0 & $0.07^{\mathrm{a}}$ & $0.06^{\mathrm{ab}}$ & $0.05^{\mathrm{b}}$ & $0.05^{b}$ & 0.003 & 0.018 \\
\hline C14:0 & 2.85 & 2.52 & 2.26 & 2.29 & 0.099 & 0.13 \\
\hline C14:1 & 0.64 & 0.50 & 0.48 & 0.50 & 0.045 & 0.65 \\
\hline C16:1 & 2.98 & 2.44 & 2.42 & 2.67 & 0.42 & 0.13 \\
\hline C17:0 & 0.81 & 0.90 & 0.89 & 0.87 & 0.018 & 0.37 \\
\hline C18:0 & 17.2 & 18.5 & 17.3 & 17.0 & 0.67 & 0.66 \\
\hline c18:1n9c & 41.1 & 41.5 & 42.8 & 42.0 & 0.72 & 0.27 \\
\hline C18:2n6c & $3.44^{b}$ & $3.65^{b}$ & $4.15^{\mathrm{ab}}$ & $4.47^{\mathrm{a}}$ & 0.13 & 0.017 \\
\hline C21:0 & 0.07 & 0.07 & 0.08 & 0.07 & 0.004 & 0.88 \\
\hline$C 20: 2$ & 0.01 & 0.02 & 0.02 & 0.01 & 0.001 & 0.27 \\
\hline$C 20: 3 n 3$ & 0.01 & 0.01 & 0.02 & 0.01 & 0.001 & 0.31 \\
\hline$C 20: 3 n 6$ & $0.13^{b}$ & $0.17^{\mathrm{ab}}$ & $0.18^{\mathrm{ab}}$ & $0.23^{\mathrm{a}}$ & 0.013 & 0.018 \\
\hline$C 20: 4 n 6$ & 0.52 & 0.80 & 0.78 & 0.63 & 0.070 & 0.48 \\
\hline$C 20: 5 n 3$ & 0.02 & 0.03 & 0.03 & 0.03 & 0.004 & 0.72 \\
\hline C22:0 & 0.05 & 0.05 & 0.05 & 0.05 & 0.003 & 0.72 \\
\hline C22:1n9 & 0.02 & 0.04 & 0.04 & 0.03 & 0.005 & 0.34 \\
\hline$C 22: 6 n 3$ & $0.01^{c}$ & $0.02^{b}$ & $0.02^{b}$ & $0.03^{\mathrm{a}}$ & 0.002 & 0.0015 \\
\hline C24:0 & 0.15 & 0.20 & 0.19 & 0.17 & 0.015 & 0.72 \\
\hline C24:1 & 0.04 & 0.05 & 0.04 & 0.04 & 0.003 & 0.97 \\
\hline
\end{tabular}

SEM, standard error of the mean; SFA, saturated fatty acid; UFA, unsaturated fatty acid; MUFA, monounsaturated fatty acid; PUFA, polyunstaturated fatty acid.

1) It is the ratio of $n-3$ to $n-6$, not the percentage of total fatty acids.

${ }^{a-c}$ Means within row with different superscripts differ significantly $(p<0.05)$.

\section{parameters}

Blood metabolites and immune parameters reflect health status of animals and the utilization of nutrients. No significant differences were found in the blood TP, ALB, GLB, NEFA, BUN, TC, TG, GLU, HDL-C, LDL-C, IgA, IgG, IgM, and TNFa among groups ( $\mathrm{p}>0.05)$, and all parameters in the normal range, which indicated that the beef cattle were in healthy status and the metabolic status had no changes due to intake of different amount of B. papyrifera silage supplemented in the diets.

Oxidative stress is an imbalance between free radical generation and antioxidant system, which is a main contributing factor inducing various disease in animals [19]. It is reported that there are flavonoids with antioxidant function naturally occurring in bark, fruit and leaves of B. papyrifera [20,21]. The nutrients with antioxidants could be used to control oxidative stress [22]. SOD is the first line of antioxidant defense that catalyzes the conversion of superoxide radical to hydrogen peroxide [23]. The blood SOD was significantly higher in 15\% group than that in control group, $5 \%$ group or $10 \%$ group $(p<0.05)$, but no statistically significant difference of blood SOD was found among control group, 5\% group, and 10\% group, which suggested that the diet supplemented with 15\% B. papyrifera could increase the antioxidative capacity. TAC represents the antioxidant response against the free radicals. The blood TAC was significantly higher in $10 \%$ group and $15 \%$ group than that in control group or 5\% group, which suggested that higher $B$. papyrifera silage in the diet increased 
blood TAC in beef cattle. MDA is one of the final products of PUFAs peroxidation and accumulates as free radicals increase. In the present study, blood MDA was significantly lower in $15 \%$ group than that in control group, $5 \%$ group or $10 \%$ group, which is consistent with the results that an increase in TAC is not parallel with an increase in MDA in cows [24]. It suggested that some antioxidants in the B. papyrifera silage could reduce the oxidation products or oxidant reaction in animal blood, which might decrease oxidative stress. Blood 8 -OHdG was significantly lower in $15 \%$ group than that in control group, $5 \%$ group, or $10 \%$ group $(\mathrm{p}<0.05)$. 8 -OHdG is the most frequently detected analyte representing DNA lesion resulting from oxidative stress and is a biomarker of the oxidative DNA damage and repair. As B. papyrifera silage increased in the diet, beef cattle had lower blood 8-OHdG, which suggested that diets with $15 \%$ B. papyrifera silage could significantly reduce DNA lesions caused by oxidative stress. The $B$. papyrifera silage might have effect on reducing oxidative stress of the beef cattle, and it could be a potential feed stuff with antioxidant capacities for beef cattle.

If the free radicals exceed the antioxidant capacity of the body system, oxidative stress will occur, which will affect the animals' growth and development in negative way [19]. It is reported that the plant pigments could improve growth performance of livestock through immune status [25] or antioxidant status [26]. In the present study, we found that $15 \%$ dietary B. papyrifera silage could affect the antioxidant system by increasing blood SOD and TAC, and decreasing MDA, and meanwhile, $15 \%$ dietary $B$. papyrifera silage improved the performance by increasing final BW, ADG, DMI, and FCR of beef cattle in 15\% group. Higher activities of SOD and TAC enzymes could reduce the oxygen radicals in the system and alleviate the oxidative damage to organisms, and lower MDA indicates less oxidative stress in animals, in which way the growth performance, such as final BW, ADG, DMI, and FCR, were improved in the present study.

\section{Meat quality traits}

Silage produces more lactic acid during fermentation, which might result in lower meat $\mathrm{pH}$, In the present study, meat $\mathrm{pH}$ was lower in $15 \%$ group that those in other groups, which might be induced by dietary B. papyrifera silage in $15 \%$ group. Meat color is an important parameter of meat quality and the first impression that the consumers have of meat. Beef cattle had higher $\mathrm{CIE} \mathrm{L}^{*}$ in $5 \%$ group, $10 \%$ group, and $15 \%$ group than that in control group, and beef cattle had higher CIE $\mathrm{a}^{*}$ in $10 \%$ group than that in control group, $5 \%$ group, or $15 \%$ group. It is reported that antioxidant treatments significantly had higher redness $\left(\mathrm{a}^{*}\right)$ values [27]. B. papyrifera contains antioxidant activities as mentioned above. It may have induced a better color value in the present study. Dark meat has a low acid content, i.e., high pH [28], which is con- sistent with our results that beef cattle fed on the diets with $B$. papyrifera silage had lower $\mathrm{pH}(\mathrm{p}<0.05)$ but higher CIE $\mathrm{L}^{*}$ and $\mathrm{a}^{*}$. Value for redness $\left(\mathrm{a}^{*}\right)$ below 9.5 are considered dark and not appreciated by consumers [29], and in the present study, beef cattle fed on the diets with $B$. papyrifera had $\mathrm{a}^{*}$ value more than 9.5. Drip loss of meat was significantly lower in $15 \%$ group than that in control group, $5 \%$ group, or $10 \%$ group. Lower drip loss indicates a higher quality meat. It is reported that dietary antioxidants could decrease meat drip loss [30] resulting from decreased membrane phospholipase activity [31] by protecting membranes from the action of phospholipases, which could cause a less substantial reduction in the fluidity and finally reduce the drip loss. In the present study, $15 \%$ B. papyrifera silage supplement in the diet could have the same function in improving meat quality.

\section{Amino acids and fatty acids composition in meat}

The profile of amino acids had no significant difference among groups. The active ingredients of $B$. papyrifera silage, such as polyphenols and flavonoids, might affect the ruminant microorganism on the fatty acid biohydrogenation but not amino acids metabolism.

Ruminant milk and meat might contain more SFA because of the biohydrogenation occurring in the rumen. There are considerable studies focusing on reducing the biohydrogenation by adding more unsaturated fatty acids of feedstuff [32,33], protecting unsaturated fatty acids [34] or supplying feedstuff against biohydrogenation [35] in ruminants' diets. In the present study, PUFA were significantly higher in 10\% and $15 \%$ groups than that in control group or $5 \%$ group $(\mathrm{p}<0.05)$, and it might due to the antimicrobial activities in the diet supplemented with $B$. papyrifera silage, as it is reported that prenylated flavonoids isolated from $B$. papyrifera have antimicrobial activity [36,37] which might affect the rumen microorganism by reducing the biohydrogenation of fatty acids in the rumen, and also dietary antioxidant activity might increase PUFA content in meat $[38,39]$. We found the similar result in milk of dairy cattle [5]. C22:6n3 (docosahexaenoic acid, DHA) of meat is higher in 5\% group, $10 \%$ group and $15 \%$ group than that in control group $(\mathrm{p}<0.05)$. Beef cattle fed on the diet supplemented with $B$. papyrifera silage had higher DHA in meat, which would be beneficial for the consumers' health.

\section{CONCLUSION}

B. papyrifera silage could be used as a new feed resource in finishing beef cattle. Beef cattle fed on diet supplemented with $15 \%$ B. papyrifera silage could increase their performance by increasing final BW, ADG, DMI, and FCR, enhance the antioxidant functions by decreasing blood 8-OHdG and MDA and increasing blood SOD and TAC, improve the meat quality 
by lowing $\mathrm{pH}$ and drip loss and increasing $\mathrm{CIE} \mathrm{L}^{*}$, increase the PUFA and DHA concentration in meat. Polyphenols and flavonoids might be the main constituents responsible for the antioxidant activity and anti-biohydrogenation in the $B$. papyrifera silage. Fatty acids in the diets are biohydrogenated by bacteria in the rumen, and we will focus further study on the effect of $B$. papyrifera silage on the rumen fermentation and bacteria composition and abundance.

\section{CONFLICT OF INTEREST}

We certify that there is no conflict of interest with any financial organization regarding the material discussed in the manuscript. Diao Q is an employee of Jonathan Technology Limited Development Company.

\section{REFERENCES}

1. Wood JD, Enser M, Fisher AV, et al. Fat deposition, fatty acid composition and meat quality: a review. Meat Sci 2008;78: 343-58. https://doi.org/10.1016/j.meatsci.2007.07.019

2. Sargolzehi MM, Naserian A, Asoodeh A, et al. Application of esterase inhibitors: A possible new approach to protect unsaturated fatty acids from ruminal biohydrogenation. Eur J Lipid Sci Technol 2015;117:1667-72. https://doi.org/10.1002/ ejlt.201400567

3 Fike JH, Allen VG, Schmidt RE, et al. Tasco-Forage: I. Influence of a seaweed extract on antioxidant activity in tall fescue and in ruminants. J Anim Sci 2001;79:1011-21. https://doi.org/ $10.2527 / 2001.7941011 \mathrm{x}$

4. Suleman KM. Suitability of home grown paper mulberry (Broussonetia papyrifera) for pulp and paper manufacture. Pak J For 1995;45:158-62. Abstract.

5. Si B, Tao H, Zhang X, et al. Effect of Broussonetia papyrifera $L$. (paper mulberry) silage on dry matter intake, milk composition, antioxidant capacity and milk fatty acid profile in dairy cows. Asian-Australas J Anim Sci 2018;31:1259-66. https://doi.org/10.5713/ajas.17.0847

6. Ko HJ, Jin JH, Kwon OS, et al. Inhibition of experimental lung inflammation and bronchitis by phytoformula containing Broussonetia papyrifera and Lonicera japonica. Biomol Ther 2011;19:324-30.

7. Yusuf AL, Adeyemi KD, Samsudin AA, Goh YM, Alimon AR, Sazili AQ. Effects of dietary supplementation of leaves and whole plant of Andrographis paniculata on rumen fermentation, fatty acid composition and microbiota in goats. BMC Vet Res 2017;13:349. https://doi.org/10.1186/s12917017-1223-0

8. Pandey KB, Rizvi SI. Plant polyphenols as dietary antioxidants in human health and disease. Oxid Med Cell Longev 2009;2:Article ID 897484. https://doi.org/10.4161/oxim.2.5. 9498
9. Haga S, Nakano M, Nakao S, et al. Seasonal foraging patterns of forest-grazing Japanese Black heifers with increased plasma total antioxidant capacity. Anim Sci J 2016;87:209-16. https:// doi.org/10.1111/asj.12408

10. Han Q, Wu Z, Huang B, et al. Extraction, antioxidant and antibacterial activities of Broussonetia papyrifera fruits polysaccharides. Int J Biol Macromol 2016;92:116-24. https://doi. org/10.1016/j.ijbiomac.2016.06.087

11. Xu ML, Wang L, Hu JH, Lee SK, Wang MH. Antioxidant activities and related polyphenolic constituents of the methanol extract fractions from Broussonetia papyrifera stem bark and wood. Food Sci Biotechnol 2010;19:677-82. https://doi.org/ 10.1007/s10068-010-0095-x

12. Van Soest PJ, Robertson JB, Lewis BA. Methods for dietary fiber, neutral detergent fiber, and nonstarch polysaccharides in relation to animal nutrition. J Dairy Sci 1991;74:3583-97. https://doi.org/10.3168/jds.S0022-0302(91)78551-2

13. Goering HK, Van Soest PJ. Forage fiber analysis (apparatus, reagents, procedures, and some applications). Washington, DC, USA: USDA-ARS; 1970 Agricultural Handbook. No. 379.

14. Bertram HC, Whittaker AK, Shorthose WR, Andersen HJ, Karlsson AH. Water characteristics in cooked beef as influenced by ageing and high-pressure treatment-an NMR micro imaging study. Meat Sci 2004;66:301-6. https://doi.org/10.1016/ S0309-1740(03)00103-7

15. Honikel KO. Reference methods for the assessment of physical characteristics of meat. Meat Sci 1998;49:447-57. https://doi. org/10.1016/S0309-1740(98)00034-5

16. Dannenberger D, Nuernberg K, Herdmann A, et al. Dietary PUFA intervention affects fatty acid- and micronutrient profiles of beef and related beef products. Foods 2013;2:295-309. https://doi.org/10.3390/foods2030295

17. Patra AK. Effects of supplementing low-quality roughages with tree foliages on digestibility, nitrogen utilization and rumen characteristics in sheep: a meta-analysis. J Anim Physiol Anim Nutr 2010:94;338-53. https://doi.org/10.1111/j.14390396.2008.00914.x

18. Patra AK. Responses of intake, digestibility and nitrogen utilisation in goats fed low-quality roughages supplemented with tree foliages. J Sci Food Agric 2009:89;1462-72. https://doi. org/10.1002/jsfa.3610

19. Lykkesfeldt J, Svendsen O. Oxidants and antioxidants in disease: oxidative stress in farm animals. Vet J 2007;173:502-11. https:// doi.org/10.1016/j.tvjl.2006.06.005

20. Du ZL, Yin ZQ, Wang L, et al. Coumarins and flavonoids from leaves of Broussonetia papyrifera. Nat Prod Res Dev 2008;20: 630-2.

21. Sun J, Liu SF, Zhang CS, et al. Chemical composition and antioxidant activities of Broussonetia papyrifera fruits. PLoS One 2012;7:e32021. https://doi.org/10.1371/journal.pone.003 2021 
22. Miller JK, Brzezinska-Slebodzinska E, Madsen FC. Oxidative stress, antioxidants, and animal function. J Dairy Sci 1993;76: 2812-23. https://doi.org/10.3168/jds.S0022-0302(93)77620-1

23. Halliwell B, Gutteridge JM. Free radicals in biology and medicine. 4th Edition. Oxford, UK: Oxford University Press; 2007. $764 \mathrm{p}$.

24. Omidi A, Fathi MH, Parker MO. Alterations of antioxidant status markers in dairy cows during lactation and in the dry period. J Dairy Res 2017;84:49-53. https://doi.org/10.1017/ S0022029916000753

25. Gupta KK, Taneja SC, Dhar KL, Atal CK. Flavonoids of Anderographis paniculata. Phytochemistry 1983;22:314-5. https:// doi.org/10.1016/S0031-9422(00)80122-3

26. Karami M, Alimon AR, Goh YM, Sazili AQ, Ivan M. Effect of dietary herbal antioxidants supplemented on feedlot growth performance and carcass composition of male goats. Am J Anim Vet Sci 2010;5:33-9. https://doi.org/10.3844/ajavsp. 2010.33.39

27. Liu F, Xu Q, Dai R, Ni Y. Effects of natural antioxidants on color stability, lipid oxidation and metmyoglobin reducing activity in raw beef patties. Acta Sci Pol Technol Aliment 2015; 14:37-44. https://doi.org/10.17306/J.AFS.2015.1.4

28. Page JK, Wulf DM, Schwotzer TR. A survey of beef muscle color and pH. J Anim Sci 2001;79:678-87. https://doi.org/10. 2527/2001.793678x

29. Khliji S, van de Ven R, Lamb TA, Lanza M, Hopkins DL. Relationship between consumer ranking of lamb colour and objective measures of colour. Meat Sci 2010;85:224-9. https:// doi.org/10.1016/j.meatsci.2010.01.002

30. Zhang Y, Luo H, Chen Y, et al. Effects of liquorice extract on the $\mathrm{pH}$ value, temperature, drip loss, and meat color during aging of Longissimus dorsi muscle in Tan Sheep. Small Rumin Res 2013;113:98-102. https://doi.org/10.1016/j.smallrumres. 2013.03.008

31. Asghar A, Gary JL, Booren AM, et al. Effects of supranutritional dietary vitamin $\mathrm{E}$ levels on subcellular deposition of a-tocopherol in the muscle and on pork quality. J Sci Food Agric 1991;57:31-41. https://doi.org/10.1002/jsfa.2740570104

32. Herdmann A, Martin J, Nuernberg G, Dannenberger D,
Nuernberg K. Effect of dietary n-3 and n-6 PUFA on lipid composition of different tissues of German Holstein bulls and the fate of bioactive fatty acids during processing. J Agric Food Chem 2010;58:8314-21. https://doi.org/10.1021/jf101 $145 \mathrm{y}$

33. Utama DT, Lee SG, Baek KH, et al. Blood profile and meat quality of Holstein-Friesian steers finished on total mixed ration or flaxseed oil-supplemented pellet mixed with reed canary grass haylage. Animal 2018;12:426-33. https:/doi.org/ 10.1017/S1751731117001707

34. Andrade EN, Polizel Neto A, Roça RO, et al. Beef quality of young Angus $\times$ Nellore cattle supplemented with rumen-protected lipids during rearing and fatting periods. Meat Sci 2014; 98:591-8. https://doi.org/10.1016/j.meatsci.2014.05.028

35. Huws SA, Scott MB, Tweed JKS, Lee MRF. Fatty acid oxidation products ('green odour') released from perennial ryegrass following biotic and abiotic stress, potentially have antimicrobial properties against the rumen microbiota resulting in decreased biohydrogenation. J Appl Microbiol 2013;115:108190. https://doi.org/10.1111/jam.12314

36. Sohn HY, Son KH, Kwon CS, Kwon GS, Kang SS. Antimicrobial and cytotoxic activity of 18 prenylated flavonoids isolated from medicinal plants: Morus alba L., Morus mongolica Schneider, Broussnetia papyrifera (L.) Vent, Sophora flavescens Ait and Echinosophora koreensis Nakai. Phytomedicine 2004;11:66672. https://doi.org/10.1016/j.phymed.2003.09.005

37. Sohn HY, Kwon CS, Son KH. Fungicidal effect of prenylated flavonol, papyriflavonol A, isolated from Broussonetia papyrifera (L.) vent. against Candida albicans. J Microbiol Biotechnol 2010;20:1397-402. https://doi.org/10.4014/jmb.1007.07026

38. Sánchez-Muniz FJ, Olivero-David R, Triki M, et al. Antioxidant activity of Hypericum perforatum L. extract in enriched n-3 PUFA pork meat systems during chilled storage. Food Res Int 2018;48:909-15. https://doi.org/10.1016/j.foodres. 2012.07.002

39. Bellés M, Del Mar Campo M, Roncalés P, Beltrán JA. Supranutritional doses of vitamin $\mathrm{E}$ to improve lamb meat quality. Meat Sci 2019;149:14-23. https://doi.org/10.1016/j.meatsci. 2018.11.002 